\title{
The Relationship Between Basal and Induced Resistance in Arabidopsis
}

\author{
Jurrian Ton, Corné M.J. Pieterse, and L.C. Van Loon
}

\subsection{Introduction}

Plants are constantly exposed to potentially pathogenic microorganisms. They possess an extensive array of passive and active defense mechanisms, and only a small proportion of microorganisms are capable of infecting the plant and causing disease. Plant resistance can be broadly defined as the plant's ability to suppress or retard the damaging activity of a pathogen. The most common type of resistance is nonhost resistance. This type of resistance protects the plant entirely from infection by most potential pathogens, and is manifested as an inability of the pathogen to cause disease upon contact with any individual of a particular plant species. In such an interaction, the pathogen is nonpathogenic.

If certain individuals within populations of the species are susceptible to some races of a pathogen but resistant to other races of the same pathogen, the interaction usually follows a gene-for-gene relationship. In compatible interactions, the pathogen is able to colonize the plant and cause disease. In contrast, in incompatible interactions, the pathogen is capable of initiating infection, but rapidiy arrested at the site of infection. The resulting race-specific or vertical resistance is generally controlled by a single dominant resistance $(R)$ gene in the host, which encodes a product that either directly or indirectly recognizes the product of a matching dominant effector (avirulence; $A v r$ ) gene expressed by the pathogen. Usually, this early recognition of the so-called avirulent pathogen gives rise to a hypersensitive response (HR). The HR involves a range of active defense mechanisms, including a form of programmed cell death at the site of infection.

Accumulation of anti-microbial compounds, fortification of cell walls, and expression of defense-related genes in the surrounding tissue all contribute to inhibit further colonization of the plant by the pathogen (Hammond-Kosack and Jones, 1996). If the invading pathogen does not carry an Avr gene that is recognized by the host, the plant fails to activate a HR. However, these so-called virulent pathogens can still be restrained by nonspecific defenses that can afford various levels of protection. This type of resistance is not well defined, but is generally referred to 
as polygenic, multigenic, horizontal, or basal resistance, and acts in slowing down the rate of disease development.

Besides primary resistance responses, plants can express an enhanced defensive capacity after being exposed to certain biotic or abiotic stimuli. This resistance is commonly referred to as induced resistance. In this chapter, we focus on the relationship between basal resistance and induced resistance.

\subsection{Signal Compounds Involved in Primary Disease Resistance}

The plant hormones salicylic acid (SA), jasmonic acid (JA), and ethylene (ET) have repeatedly been implicated in the regulation of resistance responses. In many cases, infection by both avirulent and virulent pathogens is associated with enhanced production of these regulators, and exogenous application of these compounds often results in an enhanced level of resistance (Boller, 1991; Dempsey et al., 1999; Pieterse et al., 1996, 1998, 2000; Thomma et al., 2000). Moreover, blocking the response to either of these signals can render plants more susceptible to certain pathogens or even insects (Delaney et al., 1994; Knoester et al., 1998; McConn et al., 1997; Staswick et al., 1998; Stout et al., 1999; Thomma et al., 1998; Ton et al., 2001; Van Wees et al., 1999). A central role for SA became apparent with the use of NahG transformants. Transgenic NahG plants constitutively express the bacterial NahG gene, encoding salicylate hydroxylase, which converts SA into catechol. Tobacco and Arabidopsis NahG plants show enhanced disease susceptibility to a broad range of oomycetous, fungal, bacterial, and viral pathogens (Delaney et al., 1994; Kachroo et al., 2000). Recently, a screen based on impaired accumulation of SA after pathogen infection resulted in the identification of two Arabidopsis mutants that are affected in pathogen-induced biosynthesis of SA (Nawrath and Métraux, 1999). Both mutants, sidl and sid2, displayed enhanced susceptibility to the virulent pathogens Pseudomonas syringae pv. tomato and Peronospora parasitica, demonstrating the importance of SA in the basal resistance against both the bacterial and the oomycetous pathogen. Mutants sid 1 and sid 2 are allelic with enhanced disease susceptibility mutants eds 5 (Nawrath and Métraux, 1999) and eds 16 (Wildermuth et al., 2001), respectively, which were characterized as having enhanced susceptibility to a virulent strain of the bacterial pathogen Xanthomonas campestris pv. raphani (Rogers and Ausubel, 1997) and the mildew fungus Erysiphe orontii (Wildermuth et al., 2001).

Evidence for the role of JA in pathogen resistance came predominantly from analyses of Arabidopsis mutants affected in the biosynthesis of, or responsiveness to, JA. The JA-response mutant coil has been documented as displaying enhanced susceptibility to the necrotrophic fungi Alternaria brassicicola and Botrytis cinerea (Thomma et al., 1998), and the bacterial leaf pathogen Erwinia carotovora pv. carotovora (Norman-Setterblad et al., 2000). Furthermore, coil was reported to also exhibit an altered level of basal resistance against $P$. syringae (Feys et al., 1994). Another JA-insensitive mutant of Arabidopsis, jarl, allows enhanced levels 
of growth of virulent P. syringae pv. tomato in the leaves (Pieterse et al., 1998). This clearly demonstrates that JA-dependent defenses contribute to basal resistance against these pathogens. Furthermore, both the jarl mutant and the fad 3 , fad7, fad8 triple mutant, which is defective in JA biosynthesis, exhibit susceptibility to normally nonpathogenic soilborne oomycetes of the genus Pythium (Staswick et al., 1998; Vijayan et al., 1998). These findings indicate that JA plays a role in nonhost resistance against these oomycetes. Besides involvement in resistance responses against microbial pathogens, JA also contributes to basal resistance against insects (McConn et al., 1997).

The role of ET in plant resistance seems more ambiguous. In some cases ET promotes disease development, whereas in other cases it is associated with disease resistance. For instance, ET-insensitive tomato genotypes allowed wild-type levels of growth of virulent $P$. syringae pv. tomato and $X$. campestris pv, vesicatoria, but symptoms of disease were less severe (Ciardi et al., 2000; Lund et al., 1998). In these cases, ET clearly regulates symptom expression rather than plant resistance. In Arabidopsis the ET-insensitive mutant ein $2-1$ was found to be compromised in disease development due to infection by $P$. syringae pv. tomato and $X$. campestris pv. vesicatoria (Bent et al., 1992). However, various ET-insensitive genotypes of Arabidopsis also allow enhanced levels of growth of $P$. syringae pv. tomato and $X$. campestris pv. vesicatoria (Pieterse et al., 1998; Ton et al., 2002c), indicating that ET also contributes to basal resistance. Knoester et al. (1998) reported that ET-insensitive tobacco transformed with the mutant ET receptor gene etrl-l from Arabidopsis (Tetr tobacco), displayed susceptibility to the normally nonpathogenic oomycete Pythium sylvaticum. This demonstrates that, like JA, ET plays a role in nonhost resistance against Pythium. Furthermore, several ET-insensitive mutants of Arabidopsis exhibit enhanced disease susceptibility to B. cinerea (Thomma et al., 1999), Plectosphaerella cucumerina (Berrocal-Lobo et al., 2002) and E. carotovora (Norman-Setterblad et al., 2000). These observations indicate that ET-dependent defenses contribute to basal resistance against these pathogens.

SA, JA, and ET not only regulate basal and nonhost resistance responses, but are also instrumental in boosting defense reactions in race-specific resistance. All three regulators are strongly increased during the hypersensitive reaction (e.g., Pieterse et al., 2000) and induce the expression of several defense-related genes (Maleck et al., 2000). However, plant genotypes that are impaired in the production of, or the responsiveness to, SA, JA, or ET are still capable of expressing an HR (Delaney et al., 1994; Knoester et al., 1998; Vijayan et al., 1998), indicating that $R$ gene-dependent resistance is still functional in the absence of any of these regulators.

Depending on the host-pathogen interaction, SA, JA, and ET appear to be differentially involved in basal resistance or nonhost resistance. In Arabidopsis, some pathogens have been shown to be resisted predominantly through SAdependent pathways, i.e., P. parasitica and turnip crinkle virus (TCV), whereas others are resisted predominantly through JA- and ET-dependent resistance mechanisms, i.e., A. brassicicola, B. cinerea, and E. carotovora. Table 9.1 summarizes the data demonstrating differential involvement of SA, JA, and ET in basal 
TABLE 9.1. Differential involvement of salicylic acid (SA), jasmonic acid (JA), and ethylene (ET) in the regulation of basal resistance in different plant-pathogen interactions.

\begin{tabular}{|c|c|c|c|c|c|}
\hline \multirow[b]{2}{*}{ Plant species } & \multirow[b]{2}{*}{ Pathogen } & \multicolumn{3}{|c|}{$\begin{array}{l}\text { Signals involved } \\
\text { in basal resistance }{ }^{\mathrm{a}}\end{array}$} & \multirow[b]{2}{*}{ Reference } \\
\hline & & $\mathrm{SA}$ & JA & ET & \\
\hline Arabidopsis & Peronospora parasitica & + & 0 & 0 & $\begin{array}{l}\text { Delaney et al. (1994); Thomma } \\
\text { et al. (1998) }\end{array}$ \\
\hline Arabidopsis & Turnip crinkle virus & + & 0 & 0 & Kachroo et al. (2000) \\
\hline Tobacco & Tobacco mosaic virus & + & n.d. & 0 & $\begin{array}{l}\text { Delaney et al. (1994); Knoester } \\
\text { et al. (1998) }\end{array}$ \\
\hline Tobacco & Phytophthora infestans & + & n.d. & n.d. & Delaney et al. (1994) \\
\hline Tobacco & Cercospora nicotianae & + & n.d. & n.d. & Delaney et al. (1994) \\
\hline Arabidopsis & Xanthomonas campestris & + & + & + & $\begin{array}{l}\text { Rogers and Ausubel (1997); } \\
\text { Ton et al. (2002c) }\end{array}$ \\
\hline Arabidopsis & Pseudomonas syringae & + & + & + & $\begin{array}{l}\text { Delaney et al. (1994); Pieterse } \\
\text { et al. (1998) }\end{array}$ \\
\hline Arabidopsis & $\begin{array}{l}\text { Plectosphaerella } \\
\text { cucumerina }\end{array}$ & + & + & + & Berrocal-Lobo et al. (2002) \\
\hline Arabidopsis & Pythium irregulare & n.d. & + & n.d. & Staswick et al. (1998) \\
\hline Arabidopsis & Pythium mastophorum & n.d. & + & n.d. & Vijayan et al. (1998) \\
\hline Tobacco & Pythium sylvaticum & n.d. & n.d. & + & Knoester et al. (1998) \\
\hline Arabidopsis & Alternaria brassicicola & 0 & + & + & Thomma et al. (1998, 1999) \\
\hline Arabidopsis & Botrytis cinerea & 0 & + & + & Thomma et al. (1998, 1999) \\
\hline Arabidopsis & Erwinia carotovora & 0 & + & + & Norman-Setterblad et al. (2000) \\
\hline
\end{tabular}

${ }^{\text {a Based on the enhanced susceptibility of transgenics/mutants of Arabidopsis and tobacco, impaired in }}$ the accumulation of, or responsiveness to, a particular hormone.

+ : transgenic/mutant displaying enhanced disease susceptibility compared to wild-type plants.

0 : transgenic/mutant displaying the same level of basal resistance as wild-type plants.

n.d.: not determined.

resistance. The information presented is based on enhanced susceptibility phenotypes of transgenics or mutants of Arabidopsis and tobacco that are impaired either in the accumulation of, or in the responsiveness to, any of these signal compounds.

\subsection{Induced Disease Resistance}

\subsubsection{Biologically and Chemically Induced Resistance}

Plants also possess adaptive defense mechanisms to counteract pathogen or insect attack. Upon appropriate stimulation, plants are capable of developing an enhanced defensive capacity, commonly referred to as induced resistance. The state of induced resistance depends either on defensive compounds that are produced as a result of the induction treatment, and/or on a more rapid and stronger activation of extant defense mechanisms upon challenge inoculation with a pathogen. The 
latter mechanism is variously referred to as "priming". "sensitization", or "potentiation". In either case, the resistance-inducing agent can predispose the plant to better resist subsequent pathogen attack. Induced resistance is nonspecific in being effective against a wide range of pathogens, and is typically characterized by both a restriction of pathogen growth and a reduction in disease symptoms compared to noninduced plants infected by the same pathogen (Hammerschmidt, 1999).

Induced resistance triggered by biological agents can be subdivided into two broad categories. The classical type of biologically induced resistance is variously referred to as systemic acquired resistance (SAR) or induced systemic resistance (ISR), and occurs in distal plant parts after localized infection by mainly necrosisinducing pathogens. Although the two terms are synonymous (Hammerschmidt et al., 2001), for convenience we refer to this type of induced resistance as SAR. Ross (1961) was the first to provide a detailed physiological characterization of the SAR phenomenon. He demonstrated that tobacco plants that reacted hypersensitively to tobacco mosaic virus (TMV) developed an enhanced resistance in the noninoculated upper leaves against subsequent infection by TMV or tobacco necrosis virus. Over the years, SAR has been documented as an effective defense response in various plant species against a broad range of pathogens (Kuć, 1982; Ryals et al., 1996; Sticher et al., 1997). The expression of SAR is associated with the transcriptional activation of genes encoding pathogenesis-related proteins (PRs; Van Loon, 1997) and the accumulation of these proteins. For this reason, PR mRNAs or PR-proteins are generally taken as markers for the enhanced resistance state of SAR (Kessmann et al., 1994; Ryals et al., 1996).

The second type of biologically induced resistance develops systemically in response to colonization of plant roots by selected strains of nonpathogenic rhizobacteria. In 1991, two research groups independently demonstrated that rhizospherecolonizing Pseudomonas spp. have the potential to enhance the resistance of the host plant (Van Peer et al., 1991; Wei et al., 1991). This type of induced resistance is generally not associated with the expression of $P R$ genes. In order to distinguish this type of induced resistance from pathogen-induced SAR, the term rhizobacteria-mediated ISR was introduced (Pieterse et al., 1996). Rhizobacteriamediated ISR has been demonstrated in different plant species under conditions in which the rhizobacteria remained spatially separated from the challenging pathogen (Van Loon et al., 1998), demonstrating that the phenomenon is plantmediated.

A variety of chemicals have been shown to induce resistance as well. Several of these compounds are activators of the SAR response. For instance, SA, 2,6dichloroisonicotinic acid (INA) and benzothiadiazole (BTH) induce the same set of $P R$ genes that is induced upon biological induction of SAR. Moreover, their action involves signaling steps that are also required for the expression of SAR (Lawton et al., 1996; Uknes et al., 1992; Ward et al., 1991). However, the nonprotein amino acid $\beta$-aminobutyric acid (BABA) appears to act in a different manner, as this compound has been reported to induce resistance without concomitant expression 
of PR genes (Cohen and Gisi, 1994; Zimmerli et al., 2000). The mode of action of BABA seems to be based on the priming of basal resistance mechanisms that act specifically against the attacking pathogen. Thus, BABA treatment results in an enhanced expression of SA-dependent basal defenses if the plant is invaded by Pseudomonas syringae, but stimulates SA-independent callose accumulation upon infection with Peronospora parasitica (Zimmerli et al., 2000).

\subsubsection{SAR: Triggering and Signaling}

SA was first suggested to be involved in SAR signaling based on the observation that exogenously applied SA induced resistance associated with the accumulation of PRs (Uknes et al., 1992; Van Loon and Antoniw, 1982; Ward et al., 1991; White, 1979). Furthermore, both Malamy et al. (1990) and Métraux et al. (1990) observed a strong accumulation of SA in the infected leaves of hypersensitively reacting tobacco and of cucumber with limited fungal infection, respectively. In the noninfected plant parts there was a delayed and weaker accumulation of SA that correlated with the development of SAR. Conclusive evidence for a key role of SA in SAR came from analysis of SA-nonaccumulating NahG plants. Both tobacco and Arabidopsis plants expressing the $N a h G$ gene were found to be blocked in the expression of pathogen-induced SAR, indicating that endogenous accumulation of SA is essential for SAR signaling (Gaffney et al., 1993; Lawton et al., 1995; Figure 9.1). The observation that mutants sidl and sid2 of Arabidopsis, which are both affected in pathogen-inducible biosynthesis of SA, are equally impaired in the expression of SAR against $P$. parasitica (Nawrath and Métraux, 1999) supports this conclusion.

Initially, SA was also considered a candidate for the systemically transported SAR signal. Apart from the earlier observations that accumulation of SA preceded the development of SAR and PR-gene expression in noninoculated plant parts (Malamy et al., 1990; Métraux et al., 1990), Shulaev et al. (1995) reported that ${ }^{18} \mathrm{O}$-containing SA molecules that had been synthesized locally in the infected leaf, were transported systemically throughout the plant. However, grafting experiments with tobacco strongly suggested that SA is not the systemically transported signal. Vernooij et al. (1994) demonstrated that a nontransformed scion grafted on a TMV-infected SA-nonaccumulating NahG rootstock expressed SAR, whereas a NahG scion grafted on a TMV-infected nontransformed rootstock failed to develop SAR. Similar results were obtained by graftings between nontransformed tobacco plants and transgenics exhibiting epigenetic cosuppression of the PAL gene encoding phenylalanine ammonia-lyase, causing a strongly reduced biosynthesis of SA (Pallas et al., 1996). Indeed, Smith-Becker et al. (1998) demonstrated that upon primary infection of a single cucumber leaf, the accumulation of SA in phloem fluids was preceded by a transient increase in PAL activity in the stems and petioles. These results suggested that SA is synthesized de novo in stems and petioles in response to an early mobile signal from the inoculated leaf. Even though SA is transported within the plant, it is unlikely to act as the transported SAR signal. 
Rhizobacteria

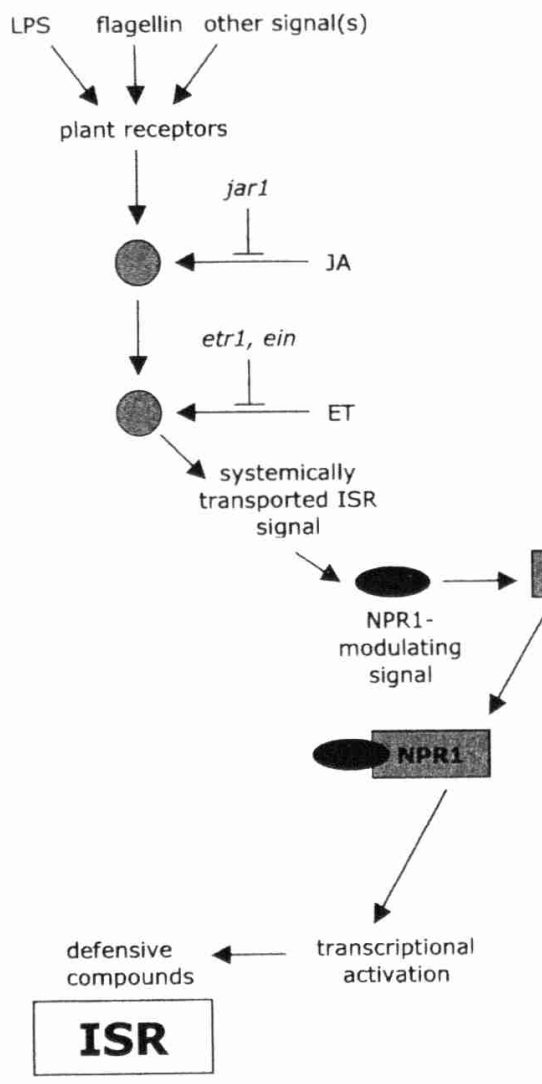

\section{Pathogen}

AVR gene product

$R$ gene product

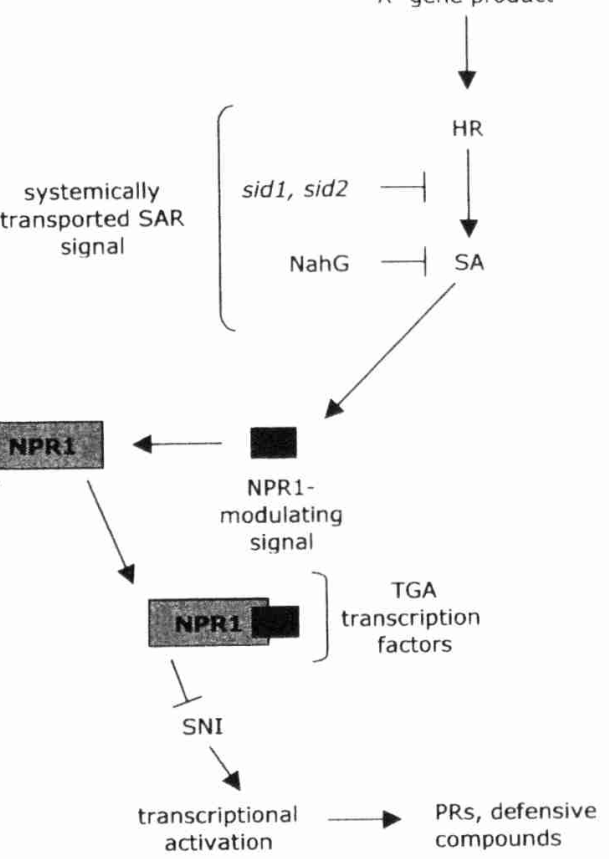

FIGURE 9.1. Proposed model for the signal transduction network controlling rhizobacteriamediated induced systemic resistance (ISR) and pathogen-induced systemic acquired resistance (SAR) in Arabidopsis thaliana. Pseudomonas fluorescens WCS417r-mediated ISR is controlled by a pathway that is dependent on responsiveness to jasmonic acid (JA) and ethylene (ET), whereas pathogen-induced SAR is controlled by a pathway that depends on accumulation of salicylic acid (SA). Both pathways require the defense regulatory protein NPR 1 that differentially regulates SA- and JA/ET dependent defense mechanisms, depending on the pathway that is activated upstream of it (Pieterse et al., 1998). LPS: lipopolysaccharide; NahG: salicylate hydroxylase; PRs: pathogenesis-related proteins; SNI: transcriptional repressor of SAR genes ( $\mathrm{Li}$ et al., 1999); TGA transcription factors: family of transcription factors interacting with SA-induced NPR1 (Després et al., 2000).

Recently, it was found that ET-insensitive Tetr tobacco plants (Knoester et al., 1998) develop less SAR, and concomitantly accumulate lower amounts of SA and fail to express $P R$ genes in the plant parts distal from primary TMV infection. Moreover, grafting experiments demonstrated that a Tetr scion grafted on 
a TMV-infected nontransformed rootstock expressed SAR, whereas a nontransformed scion on a TMV-infected Tetr rootstock did not (Verberne et al., 2003). Because the Tetr plants produce copious amounts of ET (Van Loon, unpublished results), ET itself cannot act as the mobile signal. These results clearly show that ET plays a promotive role in the generation or translocation of the mobile SAR signal.

Another essential mediator of the SAR signaling pathway is the defense regulatory protein NPR1. A screen for mutants in Arabidopsis that failed to exhibit increased expression of a $B G L 2(P R-2)$ - $\beta$-glucuronidase (GUS) reporter gene in response to SA treatment yielded the nprl mutant (Cao et al., 1994). Since then, several mutant screens based on impaired SAR expression (Delaney et al., 1995), reduced SA-induced $P R$ gene expression (Shah et al., 1997), or enhanced disease susceptibility (Glazebrook et al., 1996) all resulted in the identification of mutants allelic to $n p r 1$, illustrating the broad involvement of NPR1 in plant defense. In nprl plants, no induced resistance was evident after pretreatment with SA or its functional analogue INA, indicating that NPR1 functions downstream of the accumulation of SA in the SAR signaling pathway (Cao et al., 1994; Figure 9.1).

Clues as to the molecular basis of NPR 1 function came from analysis of its predicted protein sequence, showing the presence of ankyrin repeats, a protein motif that is known to mediate protein-protein interactions (Cao et al., 1997; Ryals et al., 1997). By use of the yeast two-hybrid system for identifying proteinprotein interactions, the NPR1 protein was recently demonstrated to interact with members of the TGA family of transcription factors (Després et al., 2000; Zhang et al., 1999; Zhou et al., 2000; Figure 9.1). A subset of these transcription factors showed specific binding to a promoter element within the $P R-1$ gene, suggesting a link between NPR 1 and the transcriptional activation of $P R-1$ genes during the onset of SAR.

A further factor implicated in the regulation of SAR is the SNI1 protein. This factor was identified by a mutant screen for genetic suppressors of the $n p r l$ mutation (Li et al., 1999). The resulting recessive snil mutant showed restored SAR expression and $P R-1$ transcription in response to treatment with INA, indicating SNI1 functions as a negative regulator in the establishment of SAR. It was proposed that SNI1 acts as a transcriptional repressor of SAR that can be counteracted by NPR1 after activation of the SA-dependent SAR pathway. Thereupon, the transcription factors of the TGA family would be allowed to activate the expression of $P R-I$ and other genes involved in the establishment of SAR (Figure 9.1).

\subsubsection{Rhizobacteria-Mediated ISR: Bacterial Determinants}

Rhizobacteria are present in large numbers on the root surface, where plant exudates and lysates provide nutrients (Lynch and Whipps, 1991). Many rhizobacterial strains can suppress soilborne diseases by antagonizing the pathogen (Bakker et al., 1991; Wei et al., 1996). Thus, in order to prove experimentally that resistance is induced by specific rhizobacterial strains, the pathogen and the rhizobacteria must remain spatially separated to prevent direct antagonistic interactions. During 
the early interaction between ISR-inducing rhizobacteria and the host plant, the rhizobacteria must produce one or more ISR-eliciting compounds that are perceived by the plant at the root surface. Under iron-limiting conditions, certain rhizobacterial strains can produce SA as an iron-scavenging siderophore (Meyer et al., 1992; Visca et al., 1993). Elicitation of ISR in tobacco by Pseudomonas fluorescens strain $\mathrm{CHAO}$ might be fully explained by the bacterial production of $\mathrm{SA}$, because treatment of plant roots with CHA0 bacteria triggered accumulation of SA-inducible PRs in the leaves (Maurhofer et al., 1994). Furthermore, transformation of $P$. fluorescens strain P3 with the SA-biosynthetic gene cluster from CHAO strongly improved the ISR-inducing capacity of P3 (Maurhofer et al., 1998).

Another strain that was suggested to elicit ISR by production of SA, is Pseudomonas aeruginosa 7NSK2. A SA-deficient mutant of 7NSK2 failed to induce systemic resistance in bean and tobacco, whereas two mutants affected in either pyoverdin or pyochelin siderophores were still capable of inducing resistance (De Meyer and Höfte, 1997). Moreover, root bacterization of NahG tobacco plants with the wild-type strain failed to induce resistance against TMV, suggesting that 7NSK2-mediated ISR is dependent on bacterially produced SA (De Meyer et al., 1999a). Indeed, SA-negative mutants of 7NSK2 lost the capacity to induce resistance in tomato to Botrytis cinerea. However, SA is used by the bacterium to produce the siderophore pyochelin, and pyochelin together with the bacterially produced antibiotic pyocyanin are now taken to be responsible for the induction of resistance through the generation of highly reactive hydroxyl radicals that cause cell damage (Audenaert et al., 2002).

Although these examples demonstrate that rhizobacteria-mediated ISR can be mediated by bacterially produced SA, resulting in the activation of the SA-dependent SAR pathway, other ISR-inducing rhizobacteria have been demonstrated to activate a SA-independent pathway (Iavicoli et al., 2003; Pieterse et al., 1996, 1998; Press et al., 1997; Ryu et al., 2003; Van Wees et al., 1997; Yan et al., 2002), implying involvement of other bacterial factors (Figure 9.1). So far, various structural and metabolic compounds have been implicated in the elicitation of rhizobacteria-mediated ISR (Van Loon et al., 1998). Purified outer membrane lipopolysaccharides (LPS), pseudobactin-type siderophores, antibiotics, and flagella of some nonpathogenic Pseudomonas strains have been shown to induce systemic resistance in selected plant species (Iavicoli et al., 2003; Leeman et al., 1995a; Van Peer and Schippers, 1992; Van Wees et al., 1997; Bakker, unpublished results). Putative receptors for the bacterial LPS have not been characterized in plants. Therefore, the molecular mechanisms behind the perception of LPS as related to ISR signaling remain unclear. Bacteria do possess specific receptors for uptake of iron-containing pseudobactin siderophores, but those are not well characterized at the protein level and their involvement in the induction of ISR has not been demonstrated. In contrast, plants have been shown to possess a sensitive perception system for bacterial flagellins (Felix et al., 1999). Recently, a flagellin receptor of Arabidopsis was characterized as a receptor kinase sharing structural and functional homology with known plant resistance genes (Gomez-Gomez and 
Boller, 2000). These results suggest that the perception of bacterial flagella can result directly in elicitation of a defense-signaling pathway. Although exogenous application of purified LPS, siderophores, or flagella can induce systemic resistance in radish and Arabidopsis (Leeman et al., 1995a; Van Peer and Schippers, 1992; Van Wees et al., 1997), bacterial mutants lacking these determinants were still able to elicit ISR in Arabidopsis (Van Wees et al., 1997; Bakker, unpublished results). This indicates that several determinants can be involved in the elicitation of rhizobacteria-mediated ISR (Figure 9.1).

\subsubsection{Rhizobacteria-Mediated ISR: A Genetic Interaction Between the Rhizobacterium and the Host}

ISR-inducing rhizobacteria show little specificity in their colonization of roots of different plant species (Van Loon et al., 1998). However, the ISR-inducing rhizobacterial strains Pseudomonas putida WCS358r and P. fluorescens WCS374r act differentially on different plant species: Arabidopsis is responsive to WCS358r, whereas radish and carnation are not (Leeman et al., 1995b; Van Peer, 1990; Van Peer and Schippers, 1992; Van Wees et al., 1997). Conversely, radish is responsive to WCS374r, whereas Arabidopsis is not. P. fluorescens strain WCS417r has the ability to elicit ISR in both plant species. These findings indicate that ISR requires a specific interaction between the plant and the nonpathogenic rhizobacterium, which must depend on specific genetic traits of both the rhizobacterium and the host plant. Thus, elicitation of ISR appears to be quite specific with regard to both the host species and the rhizobacterial strain.

In the past decade, the introduction of Arabidopsis as a model species has provided many new tools for investigating molecular and genetic aspects of plant-pathogen interactions. To unravel the genetic and molecular basis of rhizobacterially-mediated induced systemic resistance, an Arabidopsis-based assay system was developed (Pieterse et al., 1996) in which strain WCS417r was adopted as the ISR-inducing agent, and the agent of bacterial speck disease, $P$. syringae pv. tomato strain DC3000, was used as the challenging pathogen (Whalen et al., 1991). Moreover, to compare ISR to pathogen-induced SAR, a HR-eliciting strain of $P$. syringae pv. tomato, carrying the avirulence gene avrRpt2, was used as an inducer to elicit SAR.

When comparing three Arabidopsis accessions, Van Wees et al. (1997) found that the accessions Columbia (Col-0) and Landsberg erecta (Ler) were responsive to induction of ISR by WCS417r, as evidenced by a reduction in symptoms of bacterial speck and multiplication of the pathogen upon inoculation with $P$. syringae pv. tomato. In contrast, accession RLD1 failed to develop WCS417rmediated ISR against this pathogen. Root colonization of RLD1 by WCS417 $\mathrm{r}$ was of the same order as on Col-0 and Ler, indicating that RLDI supports growth of WCS417r bacteria in the rhizosphere, but that within the species Arabidopsis thaliana genetic variation is present for ISR inducibility by WCS417r. When seven additional Arabidopsis accessions were tested for their ability to express WCS417r-mediated ISR and avirulent $P$. syringae-induced SAR, all displayed 
normal levels of pathogen-induced SAR. However, only six ecotypes were capable of expressing WCS417r-mediated ISR, whereas accession Ws-0, like RLDI, was not. This WCS417r-nonresponsive phenotype of both RLDl and Ws-0 was associated with an increased susceptibility to $P$. syringae $\mathrm{pv}$. tomato infection. The $\mathrm{F}_{1}$ progenies of crosses between ISR-noninducible accessions and inducible accessions $(\mathrm{Col}-0 \times \mathrm{RLD} 1, \mathrm{RLD} 1 \times \mathrm{Col}-0$, Ws-0 $\times$ Col- 0 , Ws $-0 \times$ Ler $)$ were fully capable of expressing ISR and exhibited a relatively high level of basal resistance, similar to that of their WCS417r-responsive parent. This indicated that the potential to express ISR and the relatively high level of basal resistance against $P$. syringae pv. tomato are both inherited as dominant traits.

Analysis of the $F_{2}$ and $F_{3}$ progeny of a Col- $0 \times$ RLDl cross revealed that the potential to express ISR and basal resistance against $P$. syringae $\mathrm{pv}$. tomato cosegregate in a $3: 1$ fashion, implying that both resistance mechanisms are monogenically determined and genetically linked. Neither the responsiveness to WCS417r, nor the relatively high level of basal resistance against $P$. syringae pv. tomato were complemented in the $F_{1}$ progeny of crosses between RLDl and Ws-0, indicating that RLD1 and WS-O are both affected in the same locus. This locus, designated ISRI, controls both expression of ISR and basal resistance against $P$. syringae $\mathrm{pv}$. tomato. Thus, the naturally occurring variation in both ISR inducibility and basal resistance is based on differences at the ISRI locus. The observed association between ISR and basal resistance against $P$. syringae pv. tomato suggests that rhizobacteria-mediated ISR against $P$. syringae pv. tomato in Arabidopsis requires the presence of a single dominant gene that functions in the basal resistance response against $P$. syringae pv. tomato infection (Ton et al., 1999).

The accessions RLD1 and Ws-0 also failed to express WCS417r-mediated ISR against the bacterium Xanthomonas campestris pv. armoraciae and the oomycete $P$. parasitica. However, the level of basal resistance against these pathogens was increased relative to the ISR-inducible accession $\mathrm{Col}-0$, rather than decreased. (Ton et al., 2002b). Neither the ISRI, nor the $i s r l$ genotypes developed ISR against turnip crinkle virus (TCV), indicating that WCS417r-mediated ISR is ineffective against the virus. In contrast, both $I S R I$ and isr 1 genotypes were capable of expressing SAR against all pathogens tested, indicating that SAR functions independently of the ISRI locus.

\subsection{Differential Signaling In Pathogen-Induced SAR and Rhizobacteria-Mediated ISR}

\subsubsection{SA-Independent ISR Requires Responsiveness to Jasmonate and Ethylene}

The existence of an SA-independent pathway controlling ISR was first demonstrate in Arabidopsis when Pieterse et al. (1996) found that WCS417rmediated ISR was fully maintained in NahG plants, and not associated with the 
transcriptional activation of genes encoding SA-inducible PRs. Further studies revealed that treatment of the roots with WCS417r bacteria failed to trigger ISR in the JA-insensitive jarl or in the ET-insensitive etrl mutants, indicating that the JA and ET response pathways are essential for the establishment of this type of ISR (Pieterse et al., 1998, 2002). Moreover, using methyl jasmonate (MeJA) and the ET precursor 1-aminocyclopropane-1-carboxylate (ACC) as chemical activators of the ISR pathway, it was demonstrated that JA functions upstream of ET in the ISR signaling pathway (Pieterse et al., 1998; Figure 9.1).

An SA-independent but JA- and ET-dependent pathway was also established for the induction of systemic resistance by Bacillus pumilus SE34 and P. fluorescens 89B61 in tomato against late blight, caused by Phytophthora infestans (Yan et al., 2002). By contrast, induction of systemic resistance in Arabidopsis by P. fluorescens CHA0 to Peronospora parasitica was blocked in the eirl mutant, but not in the ethylene-insensitive etr1 or ein 2 mutants (Iavicoli et al., 2003). Whereas induction of resistance in Arabidopsis to P. syringae pv. tomato by Serratia marcescens 90-166 required JA or ET signaling, SA-independent induction by $P$. fluorescens $89 \mathrm{~B} 61$ did not, and induction by B. pumilus T4 was independent of NPR1 (Ryu et al., 2003). These observations indicate variations in the requirement for elicitation of ISR by different bacterial strains in Arabidopsis.

To further investigate the roles of JA and ET in ISR signaling, the levels of these signaling molecules were determined in plants upon root bacterization with WCS417r. Both systemically and at the site of application of the bacteria, JA content and the level of ET evolution remained unaltered upon ISR induction (Knoester et al., 1999; Pieterse et al., 2000). Also, LOX2-cosuppressed S-12 plants, that are blocked in lipoxygenase-mediated production of JA after wounding (Bell et al., 1995 ) and pathogen infection (Pieterse et al., 2000), were normally responsive to bacterial induction treatments (Pieterse et al., 2000), indicating that ISR can be expressed in the absence of increased JA levels. These data suggest that the JA and ET dependency of ISR is not based on an enhancement of JA and ET production, but rather on an enhanced sensitivity to these hormones.

Since modulation of ET sensitivity in ET-response mutants of Arabidopsis results in an altered level of basal expression of ET-responsive genes (Knoester et al., 1999), increased expression would be expected if ISR-expressing plants have enhanced sensitivity to JA and ET. However, when Van Wees et al. (1999) analyzed a large set of known, well-characterized defense-related genes of Arabidopsis upon induction by WCS417r, none of these defense-related genes were up-regulated in roots or leaves of ISR-expressing plants. Furthermore, a differential screening from a cDNA library representing mRNAs of ISR-expressing leaves did not result in the identification of genes that were significantly up-regulated upon induction of ISR (Van Wees, 1999). Thus, WCS417r-mediated ISR, unlike pathogen-induced $\mathrm{SAR}$, is neither associated with major changes in $P R$ gene expression, nor with changes in the expression of JA- and ET-inducible genes. An alternative explanation for the JA- and ET-dependency of ISR could be that basal levels of both hormones are required for priming the plant to be conducive to ISR signaling (Figure 9.1). 
To further elucidate the role of ET in the ISR signaling pathway, Knoester et al. (1999) tested several well-characterized Arabidopsis mutants that are disturbed in different steps of the ET-response pathway. None of these mutants expressed ISR upon treatment of the roots with WCS417r, demonstrating that all known components of the ET signaling pathway are required for the expression of ISR. Mutant eirl, which is insensitive to ET in the roots only, did not develop ISR after application of WCS417 $r$ to the roots, but did after application to the leaves. Based on this observation it was postulated that ET signaling is required at the site of application of the inducer, suggesting that, similar to SAR in tobacco (Knoester et al., 2001; Verberne et al., 2003), ET is involved in the generation or translocation of the systemically transported signal (Figure 9.1). The finding that JA signaling functions upstream of ET signaling in the ISR pathway (Pieterse et al., 1998) implies that JA signaling is required at the site of WCS417r application as well (Figure 9.1). However, these findings do not rule out the possibility that components of the JA and ET response are also required for the expression of ISR in tissues distant from the site of application of the inducing bacterium.

\subsubsection{The Dual Role of NPRI in Induced Resistance}

Although the signaling pathways controlling WCS417r-mediated ISR and pathogen-induced SAR clearly differ, both pathways share at least one common signaling component. Pieterse et al. (1998) reported that the $n \mathrm{prl}$ mutant of Arabidopsis is not only impaired in the expression of SAR, but also fails to express ISR after treatment of the roots with WCS417 $\mathrm{r}$ bacteria. This demonstrated that NPR 1 is required for the establishment of both SA-dependent SAR and JA-and ET-dependent ISR. Elucidation of the sequence of ISR signaling events revealed that NPR 1 functions downstream of the JA and ET response in the ISR pathway, indicating that NPR1 regulates the activation of both SA-dependent defense-related genes and so far unidentified JA- and ET-dependent defense components (Pieterse et al., 1998). Thus, NPR1 differentially regulates either SA- or JA/ET-dependent defense responses, depending on the pathway that is activated upstream of it (Figure 9.1). Recently, Van Wees et al. (2000) demonstrated that simultaneous activation of SAR and ISR results in an enhanced level of protection against $P$. syringae pv. tomato. In addition, it was demonstrated that simultaneous activation of both responses is not associated with enhanced levels of NPRI transcription. Thus, the constitutive level of NPR1 is sufficient for the expression of both defense responses.

Further evidence suggesting a regulatory function of NPR1 in SA-independent defense responses came from a genetic study by Clarke et al. (1998). A screen for mutants in transgenic Arabidopsis constitutively expressing the BGL2-GUS reporter gene yielded the identification of the dominant $\operatorname{cpr} 6$ mutant. This mutant possessed enhanced levels of SA in combination with enhanced pathogen resistance and increased constitutive expression of both SA- and JA-responsive genes. The enhanced resistance of cpr6 against $P$. syringae pv. maculicola was abolished in the cpr6, nprl double mutant, despite unaltered constitutive expression of 
SA-inducible $P R$ genes. This not only indicates that $P R$ genes can be controlled in a NPR 1-independent manner, but also illustrates that cpr6-mediated resistance, like WCS417r-mediated ISR, is controlled through an NPR1-dependent pathway that is not associated with SA-inducible $P R$ gene expression.

\subsection{Induced Resistance in Relation to Basal Resistance}

\subsubsection{Induced Resistance is Expressed as an Enhancement of Basal Resistance}

The enhanced defensive capacity of plants expressing induced resistance can be based on physiological and biochemical changes in response to the resistanceinducing treatment, or on mechanisms that are expressed only after pathogen challenge of the induced tissues. In the case of SAR, accumulation of PRs is triggered as a result of the inducing treatment. Certain PRs that are synthesized de novo upon SAR induction have antifungal activity. However, the contribution of PRs to induced resistance remains uncertain (Van Loon, 1997). PRs may contribute to resistance against oomycetes, fungi, or bacteria by their hydrolytic action on pathogen cell walls, but it is difficult to envisage a function in viral resistance. Despite several attempts in the case of WCS417r-mediated ISR, metabolic changes before challenge inoculation with a pathogen have not been identified. This suggests that the enhanced defensive capacity of plants expressing induced resistance is largely based on increased post-challenge defense responses. Indeed, the plant may become sensitized to activate appropriate defense mechanisms faster and more strongly upon infection with a challenging pathogen.

Examples of primed expression of defense mechanisms have been reported for both SAR and ISR. Notably, these mechanisms also operate in noninduced plants, but they occur at lower frequency, intensity, or at a later stage during pathogen attack (Hammerschmidt, 1999). For example, noninduced cucumber plants upon infection with Colletotrichum lagenarium develop papillae at the sites of attempted penetration of the fungus. These papillae contain callose and lignin, which are thought to act as a barrier to pathogen penetration. In induced plants, the enhanced resistance was associated with a faster formation of significantly more papillae at the sites of appressoria formation than in noninduced plants. Moreover, the papillae in induced plants contained higher amounts of callose and lignin (Hammerschmidt and Kuć, 1982; Kovats et al., 1991). Likewise, Arabidopsis plants pre-treated with the chemical inducer BABA and subsequently challenged with $P$. parasitica displayed intensified deposition of callose-rich papillae at the sites of pathogen penetration (Zimmerli et al., 2000). This suggests that the induced resistance against $C$. lagenarium and $P$. parasitica is realized through a primed expression of papilla formation, a mechanism that also determines the level of basal resistance against these pathogens. A stimulation of other defense mechanisms, such as accumulation of hydroxyproline-rich glycoproteins and increased peroxidase activity was also observed (Hammerschmidt, 1999). Similarly, challenge-inoculated carnation 
plants expressing rhizobacteria-mediated ISR against Fusarium oxysporum f.sp. dianthi, accumulated phytoalexins earlier and to a greater extent than noninduced plants (Van Peer et al., 1991). In all these examples, the induced resistance appeared as a faster and stronger expression of defense mechanisms that also contributed to the basal resistance of noninduced plants. These findings suggest that the enhanced defensive capacity of plants expressing induced resistance is largely based on enhanced expression of extant basal defense mechanisms.

Induced resistance as an enhancement of extant basal resistance would imply that plant genotypes differing in genetically determined basal resistance could differ in the extent to which induced resistance can be expressed. Indeed, in carnation WCS417r-mediated ISR against Fusarium wilt was considerably more effective in the moderately resistant cultivar Pallas than in the susceptible cultivar Lena (Van Peer et al., 1991). An apparently opposite relationship was described by Liu et al. (1995), who reported that $P$. putida 89B-27-mediated ISR in cucumber against Colletotrichum orbiculare was expressed in three susceptible cultivars, but not in a resistant one. This result could be interpreted in the sense that in the already highly resistant cultivar defenses could not be further enhanced upon induction of ISR. However, a correlation between induced resistance and basal resistance is not always apparent. For example, both susceptible and moderately resistant radish cultivars were capable of expressing rhizobacteria-mediated ISR against Fusarium wilt (Leeman et al., 1995b).

\subsubsection{Induced Resistance as Primed Expression of SA-Dependent or JA/ET-Dependent Defenses}

Interestingly, SA, JA, and ET have all been implicated in the regulation of priming of defense responses (Conrath et al., 2002). For instance, parsley cells pretreated with either JA, SA, or its functional analogues, showed primed accumulation of active oxygen species, secretion of cell wall phenolics, accumulation of coumarin phytoalexins, and PAL gene expression upon treatment with the Pmg elicitor of Phytophthora megasperma f.sp. glycinea (Katz et al., 1998; Kauss et al., 1992, 1993, 1994; Thulke and Conrath, 1998). Notably, in intact plants these defense responses all contribute to local resistance responses after primary pathogen attack. In tobacco, it was demonstrated that SAR-expressing plants showed primed $P R-10$ and PAL gene expression upon infection with different pathogenic pseudomonads (Mur et al., 1996). In Arabidopsis, Lawton et al. (1994) showed that plants preexposed to ET were sensitized to SA-induced $P R-I$ gene expression, suggesting that ET potentiates defense mechanisms that contribute to SAR. Indeed, ET-insensitive tobacco plants expressing the mutant etrl-I gene of Arabidopsis showed a reduced SAR response (Knoester et al., 2001).

Analysis of mutants and transgenics, particularly in Arabidopsis and tobacco, revealed that signaling pathways controlling basal resistance are often involved also in induced resistance responses. For instance, as described in Section 9.2, SAnonaccumulating NahG plants of both Arabidopsis and tobacco exhibit enhanced susceptibility to a variety of pathogens (Delaney et al., 1994). At the same time, 
they are affected in the expression of pathogen-induced SAR (Gaffney et al., 1993; Lawton et al., 1995). A similar correlation was found for Arabidopsis plants mutated in the NPRI gene. Those mutants are not only blocked in the expression of pathogen-induced SAR (Cao et al., 1994; Delaney et al., 1995) and WCS417rmediated ISR (Pieterse et al., 1998), but their level of basal resistance is also lower against $P$. syringae and $P$. parasitica (Delaney et al., 1995; Glazebrook et al., 1996). Similarly, the JA-insensitive jarl mutant and the ET-insensitive etrl mutants are affected in the expression of WCS417r-mediated ISR (Pieterse et al., 1998), and concurrently allow tenfold higher levels of growth of $P$. syringae pv. tomato in the leaves than wild-type plants upon primary infection.

Phenotypically, mutants jarl and etrl strongly resemble the is 1 phenotype of accessions RLD1 and Ws-0. Therefore, we considered the possibility that ecotypes RLD1 and WS-0 are impaired in either JA or ET signaling, and whether the ISR I locus might be involved. Compared to the ISR-inducible accession Col-0, accessions RLD1 and Ws-0 were not affected in JA-induced inhibition of root growth or expression of the JA-responsive vegetative storage protein gene AtVSP, suggesting that the ISRI locus is not involved in JA signaling. However, RLD1 and Ws-0 were affected in their ET-dependent triple response and showed reduced expression of the ET-responsive hevein gene $H E L$, and the plant defensin gene PDF 1.2 after exogenous application of ACC. Moreover, in contrast to Col-0, both RLD1 and $\mathrm{Ws}_{\mathrm{S}-0}$ did not develop resistance against $P$. syringae pv. tomato after treatment of the leaves with ACC. Analysis of the $F_{2}$ and $F_{3}$ progeny of a cross between Col-0 (ISRI/ISRl) and RLD1 (isrl/isrl) revealed that the reduced sensitivity to ET cosegregates with the recessive alleles of the ISRI locus (Ton et al., 2001). These results indicated that the ISRI locus encodes a novel component of the ET-response pathway, which is required for the expression of rhizobacteria-mediated ISR. Hence, the observed association between ISRnoninducibility and reduced basal resistance against $P$. syringae pv. tomato in the Arabidopsis accessions RLD1 and Ws- 0 can be attributed to a reduced sensitivity to ET.

Thus, in many cases there seems to be a correlation between the presence of a certain level of basal resistance and the capacity of a plant to develop induced resistance. Nevertheless, various ET-insensitive mutants of Arabidopsis are unaffected in their SAR response (Knoester et al., 1999; Lawton et al., 1994, 1995). Interestingly, upon challenge inoculation with $P$. syringae pv. tomato, SARexpressing Arabidopsis plants showed a primed expression of SA-inducible $P R$ genes (Cameron et al., 1999; Van Wees et al., 1999), whereas ISR-expressing Arabidopsis plants displayed a primed expression of the JA-inducible AtVSP gene (Van Wees et al., 1999). These results clearly indicate that both types of induced resistance are associated with priming of different defense responses. Therefore, it is tempting to speculate that SAR is achieved through a primed expression of SAdependent basal defenses, whereas WCS417r-mediated ISR is achieved through a primed expression of JA/ET-dependent basal resistance. A model is schematically represented in Figure 9.2. 


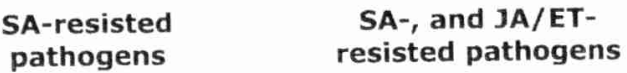

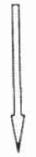

SA

pathway

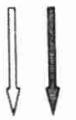

Specific set of bas

(I)
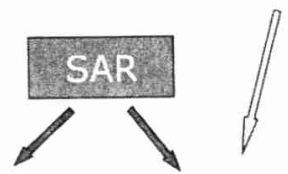

SA pathway

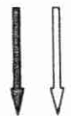

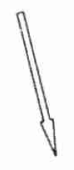

JA/ET pathway

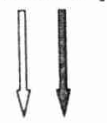
rofense mechanism:

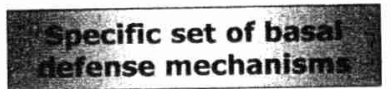

(I) + (II)
JA/ET-resisted pathogens

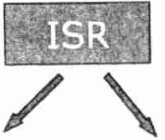

JA/ET pathway

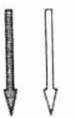

FIGURE 9.2. Model explaining pathogen-induced SAR and rhizobacteria-mediated ISR as a primed expression of basal defense mechanisms. SA-dependent basal defense mechanisms (I) are primed in SAR-induced plants. Consequently, infection of SAR-expressing tissue triggers a faster and stronger activation of SA-dependent defense mechanisms, resulting in an effective protection against pathogens that are resisted through SA-dependent basal resistance, i.e., P. parasitica and TCV. Conversely, pathogen infection of plants pretreated with ISR-inducing WCS417r bacteria results in priming of JA/ET-dependent basal defense mechanisms (II). Accordingly, ISR-expressing tissues show a faster and stronger expression of JA/ET-dependent defense mechanisms upon infection, resulting in an effective protection against pathogens that are resisted through JA/ET-dependent basal resistance, i.e., $A$. brassicicola. Pathogens that are resisted through a combination of SA and JA/ET-dependent basal resistance, i.e., P. syringae and X. campestris, are sensitive to both SAR and ISR (I) + (II).

\subsubsection{Impaired Induced Resistance as a Result of Reduced SA-Dependent or JA/ET-Dependent Basal Resistance}

Because of the association between induced resistance and basal resistance, a collection of Arabidopsis eds mutants with enhanced disease susceptibility to pathogenic P. syringae bacteria (Glazebrook et al., 1996; Volko et al., 1998) was screened for their potential to express rhizobacteria-mediated ISR and pathogeninduced SAR against $P$. syringae pv. tomato. Out of 11 eds mutants tested, eds $4-I$, eds 8-1, and eds 10-1 were nonresponsive to induction of ISR by WCS417r, whereas mutants eds5-1 and eds 12-1 were nonresponsive to induction of SAR (Ton et al., 2002a). While eds5-1 is known to be allelic to sidl, and blocked in the synthesis of SA (Nawrath and Métraux, 1999), further analysis of eds 12-1 revealed that the SAR-impaired phenotype of this mutant is caused by a reduced sensitivity to SA. Analysis of the ISR-impaired $e d s$ mutants revealed that they are insensitive to induction of resistance by MeJA (eds4-1, eds8-1, and eds 10-1) or ACC (eds4-I 
and eds 10-I). Moreover, eds4-1 and eds8-1 showed reduced expression of the PDF1.2 gene after treatment with MeJA and ACC, which was associated with a reduced sensitivity to either ET (eds4-1) or MeJA (eds8-1). Although blocked in rhizobacteria-, MeJA-, and ACC-induced protection, mutant eds $10-1$ showed normal responsiveness to both MeJA and ACC. Together, these results indicated that EDS 12 is required for SAR and acts downstream of SA, whereas EDS4, EDS8, and EDS10 are required for ISR and act in either the JA response (EDS8), the ET response (EDS4), or downstream of the JA and ET response (EDS10) in the ISR signaling pathway (Ton et al., 2002a). Together, these results not only confirm the dual involvement of JA, ET, and SA in induced resistance and basal resistance, but they also demonstrate that $P$. syringae is resisted through a combined action of JA-, ET-, and SA-dependent basal resistance.

\subsubsection{Induced Resistance as an Enhancement of SA-Dependent or JA/ET-Dependent Basal Resistance}

Over the past years, plant genotypes affected in SA, JA, or ET signaling have been linked repeatedly to enhanced disease susceptibility to specific pathogens and even insects (Delaney et al., 1994; Knoester et al., 1998; McConn et al., 1997; Staswick et al., 1998; Vijayan et al., 1998). Evidence is accumulating that SA-, JA-, and ET-dependent defenses contribute to basal resistance against different pathogens. JA- and ET-insensitive Arabidopsis genotypes exhibit enhanced susceptibility to necrotrophic pathogens, i.e., A. brassicola and B. cinerea, indicating that basal resistance against these pathogens is, at least in part, conferred by JA- and ETdependent defenses (Thomma et al., 1998, 1999). Conversely, genotypes impaired in SA accumulation exhibit enhanced susceptibility to predominantly biotrophic pathogens, i.e., P. parasitica and TCV (Kachroo et al., 2000; Nawrath and Métraux, 1999; Thomma et al., 1998), indicating that these pathogens are predominantly resisted through $\mathrm{SA}$-dependent defenses.

Because SA is a key regulator of SAR, whereas JA and ET sensitivity are required for ISR, SAR and ISR might also be differentially effective against different pathogens. Indeed, the fungus A. brassicicola, which is resisted through JA/ET-dependent basal defenses, was inhibited considerably in plants expressing WCS417r-mediated ISR, whereas expression of SAR induced by either INA or avirulent $P$. syringae was ineffective against this pathogen (Ton et al., 2002c). Conversely, $P$. parasitica and TCV, which are both resisted through predominantly SA-dependent basal defenses, were strongly inhibited by the expression of SAR, while ISR yielded only weak and no protection, respectively. SAR induced by avirulent $P$. syringae and ISR triggered by WCS417r bacteria were equally effective against $P$. syringae pv. tomato and $X$. campestris pv. armoraciae, which are resisted through a combination of SA-, JA-, and ET-dependent basal defenses (Ton et al., 2002c). Thus, ISR is predominantly effective against pathogens that are resisted through basal defenses that are activated by a JA/ET-dependent mechanism, 
whereas SAR is more effective against pathogens that are resisted through SAdependent basal defenses.

- As discussed in Section 9.5.2. Arabidopsis genotypes affected in JA/ETdependent basal resistance against $P$. syringae are impaired in WCS417r-mediated ISR, whereas genotypes affected in SA-dependent basal resistance against $P$. syringae are impaired in avirulent pathogen-induced SAR. In accordance with the earlier notion that induced disease resistance is an enhancement of genetically determined basal resistance by which extant defense mechanisms are expressed earlier and to higher levels (Van Loon, 1997), these results strongly suggest that WCS417r-mediated ISR involves an enhancement of JA- and ET-dependent basal resistance, whereas SAR constitutes an enhancement of SA-dependent basal resistance. Consequently, pathogens such as $P$. syringae and $X$. campestris, which are resisted through a combined action of SA-dependent and JA/ET-dependent basal defenses, are sensitive to both SAR and ISR (Pieterse et al., 1998; Ton et al., 2002c). As a result, Arabidopsis RLD1 and Ws-0 can still enhance their defensive capacity through the expression of SAR, even though they have lost their ability to express ISR.

\subsection{Combining SAR and ISR as a Method to Improve Biocontrol of Plant Diseases}

Van Wees et al. (2000) demonstrated that combined treatment of Arabidopsis with ISR-inducing WCS417r and SAR-inducing avirulent $P$. syringae results in an enhanced level of induced protection against $P$. syringae pv. tomato. Moreover, the resistance of the constitutively SAR-expressing mutant $\mathrm{cprl}$ could be increased further by treatment of the roots with ISR-inducing WCS417r bacteria. This indicates that the JA/ET-dependent ISR pathway and the SA-dependent SAR pathway act additively on the level of protection against this pathogen. $X$. campestris $\mathrm{pv}$. armoraciae is also resisted through a combined action of JA/ET-dependent and SA-dependent defense pathways (Ton et al., 2002c). Therefore, one can predict that simultaneous activation of SAR and ISR will result in an enhanced level of protection against $X$. campestris pv. armoraciae as well. Indeed, recent observations confirmed that simultaneous activation of WCS417r-mediated ISR and avirulent $P$. syringae-induced SAR conferred enhanced protection against this bacterium (Van Pelt and Pieterse, unpublished results). Additionally, SAR and ISR seem to confer differential protection against different types of pathogens. Thus, combining SAR and ISR can protect the plant against a wider spectrum of pathogens, and even result in an additive level of induced protection against pathogens that are resisted through both the JA/ET- and the SA-dependent pathways. This additive action of pathogen-induced SAR and WCS417r-mediated ISR in resistance against pathogenic bacteria is at variance with the reported antagonism between SA-dependent SAR and JA-induced resistance against insects (Stout et al., 1999). However, this apparent discrepancy can be explained by the fact that induced 
resistance against insects depends on a signaling pathway requiring enhanced accumulation of JA (McConn et al., 1997), whereas WCS417r-mediated ISR is dependent on sensitivity to JA and ET rather than elevated levels of these regulators (Pieterse et al., 2000).

Biological control of plant diseases is still in its infancy, because the level of protection and its consistency are generally not sufficient to compete with conventional methods of disease control. One approach to improve the efficacy and consistency of biological control against soilborne pathogens is to apply combinations of antagonistic microorganisms with different mechanisms of action (De Boer, 2000). Alternatively, microorganisms can be engineered to express diseasesuppressive traits constitutively at high levels. Manipulation of the plants by introducing race-specific $R$ genes into plants is another attractive approach, because it renders the plant completely resistant to a pathogen. However, resistance based on gene-for-gene resistance, offers protection against only a single pathogen, and the pathogen can overcome the resistance by mutation. Transgenic approaches to engineer durable and broad-spectrum resistance are promising, but still under development. Our findings that the combination of SAR and ISR confers protection against a wider spectrum of pathogens and results in enhanced levels of protection against specific bacterial pathogens (Van Wees et al., 2000), offers great potential for integrating both forms of induced resistance in future agricultural practices.

The chemical plant activator BION suppresses plant diseases through BTHmediated activation of the SAR response (Friedrich et al., 1996; Lawton et al., 1996). Nevertheless, SAR does not protect the plant against necrotrophic pathogens such as A. brassicicola and B. cinerea (Thomma et al., 1998). Furthermore, BION has been reported to reduce plant growth and seed set under field conditions (Heil et al., 2000). By contrast, resistance-inducing rhizobacteria can improve plant growth under field conditions. This rhizobacteria-mediated growth promotion results mainly from the antagonistic activity against soilborne pathogens and other deleterious microorganisms (Kloepper et al., 1980; Schippers et al., 1987). Furthermore, resistance-inducing rhizobacteria, in general, do not solely induce resistance through JA/ET-dependent ISR. Some rhizobacteria appear to activate the SAR response through production of SA at the root surface (De Meyer et al., 1999b; De Meyer and Höfte, 1997; Maurhofer et al., 1994, 1998). Agricultural inoculants containing combinations of selected ISR-inducing rhizobacteria and SA-producing rhizobacteria could have an advantage in that three diseasesuppressive mechanisms, i.e., microbial antagonism, ISR- and SAR-action, are combined. Therefore, activation of both SAR and ISR through rhizobacterial treatments offers not only great potential for improving the efficacy and consistency of biocontrol with plant growth-promoting rhizobacteria, but would also broaden its spectrum of effectiveness. Furthermore, elucidation of the molecular mechanisms underlying ISR and SAR may lead to the identification of key regulatory components that could be engineered to constitutive expression in crop plants, in order to enhance their level of basal resistance against a broad spectrum of pathogens. 


\section{References}

Audenaert, K., Pattery, T., Cornelis, P., and Höfte, M. 2002. Induction of systemic resistance to Botrytis cinerea in tomato by Pseudomonas aeruginosa 7NSK2: role of salicylic acid, pyochelin, and pyocyanin. Mol. Plant Microbe Interact. 15:1147-1156.

Bakker, P.A.H.M., Van Peer, R., and Schippers, B. 1991. Suppression of soil-borne plant pathogens by fluorescent pseudomonads: mechanisms and prospects. In Biotic Interactions and Soil-Borne Diseases, eds. A.B.R. Beemster, G.J. Bollen, M. Gerlagh, M.A. Ruissen, B. Schippers, and A. Tempel, pp. 217-230. Amsterdam, The Netherlands: Elsevier Scientific Publishers.

Bell, E., Creelman, R.A., and Mullet, J.E. 1995. A chloroplast lipoxygenase is required for wound-induced accumulation of jasmonic acid in Arabidopsis. Proc. Natl. Acad. Sci. USA 92:8675-8679.

Bent, A.F., Innes, R.W., Ecker, J.R., and Staskawicz, B.J. 1992. Disease development in ethylene-insensitive Arabidopsis thaliana infected with virulent and avirulent Pseudomonas and Xanthomonas pathogens. Mol. Plant Microbe Interact. 5:372378.

Berrocal-Lobo, M., Molina, A., and Solano, R. 2002. ETHYLENE-RESPONSE-FACTOR1 in Arabidopsis confers resistance to several necrotrophic fungi. Plant J. 29:23-33.

Boller, T. 1991. Ethylene in pathogenesis and disease resistance. In The Plant Hormone Ethylene, eds. A.K. Mattoo, and J.C. Suttle, pp. 293-314. Boca Raton: CRC Press.

Cameron, R.K., Paiva, N.C., Lamb, C.J., and Dixon, R.A. 1999. Accumulation of salicylic acid and $P R-1$ gene transcripts in relation to the systemic acquired resistance (SAR) response by Pseudomonas syringae pv. tomato in Arabidopsis. Physiol. Mol. Plant Pathol. 55:121-130.

Cao, H., Bowling, S.A., Gordon, A.S., and Dong, X. 1994. Characterization of an Arabidopsis mutant that is nonresponsive to inducers of systemic acquired resistance. Plant Cell 6:1583-1592.

Cao, H., Glazebrook, J., Clarke, J.D., Volko, S., and Dong, X. 1997. The Arabidopsis NPR I gene that controls systemic acquired resistance encodes a novel protein containing ankyrin repeats. Cell 88:57-63.

Ciardi, J.A., Tieman, D.M., Lund, S.T., Jones, J.B., Stall, R.E., and Klee, H.J. 2000. Response to Xanthomonas campestris pv. vesicatoria in tomato involves regulation of ethylene receptor gene expression. Plant Physiol. 123:81-92.

Clarke, J.D., Liu, Y., Klessig, D.F., and Dong, X. 1998. Uncoupling PR gene expression from NPR 1 and bacterial resistance: characterization of the dominant Arabidopsis cpr6-I mutant. Plant Cell 10:557-569.

Cohen, Y., and Gisi, U. 1994. Systemic translocation of ${ }^{14}$ C-DL-3-aminobutyric acid in tomato plants in relation to induced resistance against Phytophthora infestans. Physiol. Mol. Plant Pathol. 45:441-456.

Conrath, U., Pieterse, C.M.J., and Mauch-Mani, B. 2002. Priming in plant-pathogen interactions. Trends Plant Sci. 7:210-216.

De Boer, M. 2000. Combining Pseudomonas strains to improve biological control of fusarium wilt in radish. Ph. D. thesis, Utrecht University, The Netherlands.

De Meyer, G., Audenaert, K., and Höfte, M. 1999a. Pseudomonas aeruginosa 7NSK2induced systemic resistance in tobacco depends on in planta salicylic acid accumulation, but is not associated with PR-Ia expression. Eur. J. Plant Pathol. 105:513-517.

De Meyer, G., Capieau, K., Audenaert, K., Buchala, A., Métraux, J.-P., and Höfte, M. 1999b. Nanogram amounts of salicylic acid produced by the rhizobacterium Pseudomonas 
aeruginosa 7NSK2 activate the systemic acquired resistance pathway in bean. Mol. Plant-Microbe Interact. 12:450-458.

De Meyer, G., and Höfte, M. 1997. Salicylic acid produced by the rhizobacterium Pseudomonas aeruginosa 7NSK2 induces resistance to leaf infection by Botrytis cinerea on bean. Phytopathology 87:588-593.

Delaney, T.P., Friedrich, L., and Ryals, J.A. 1995. Arabidopsis signal transduction mutant defective in chemically and biologically induced disease resistance. Proc. Natl. Acad. Sci. USA 92:6602-6606.

Delaney, T.P., Uknes, S., Vernooij, B., Friedrich, L., Weymann, K., Negrotto, D., Gaffney, T., Gut-Rella, M., Kessmann, H., Ward, E., and Ryals, J. 1994. A central role of salicylic acid in plant disease resistance. Science 266:1247-1250.

Dempsey, D.A., Shah, J., and Klessig, D.F. 1999. Salicylic acid and disease resistance in plants. Crit. Rev. Plant Sci. 18:547-575.

Després, C., Delong, C., Glaze, S., Liu, E., and Fobert, P.R. 2000. The Arabidopsis NPR1/NIM1 protein enhances the DNA binding activity of a subgroup of the TGA family of bZIP transcription factors. Plant Cell 12:279-290.

Felix, G., Duran, J.D., Volko, S., and Boller, T. 1999. Plants have a sensitive perception system for the most conserved domain of bacterial flagellin. Plant J. 18:265276.

Feys, B.J.F., Benedetti, C.E., Penfold, C.N., and Turner, J.G. 1994. Arabidopsis mutants selected for resistance to the phytotoxin coronatine are male sterile, insensitive to methyl jasmonate, and resistant to a bacterial pathogen. Plant Cell 6:751-759

Friedrich, L., Lawton, K., Ruess, W., Masner, P., Specker, N., Gut-Rella, M.G., Meier, B., Dincher, S., Staub, T., Métraux, J.-P., Kessmann, H., and Ryals, J. 1996. A benzothiadiazole derivate induces systemic resistance in tobacco. Plant J. 10:61-70.

Gaffney, T., Friedrich, L., Vernooij, B., Negrotto, D., Nye, G., Uknes, S., Ward, E., Kessmann, H., and Ryals, J. 1993. Requirement of salicylic acid for the induction of systemic acquired resistance. Science 261:754-756.

Glazebrook, J., Rogers, E.E., and Ausubel, F.M. 1996. Isolation of Arabidopsis mutants with enhanced disease susceptibility by direct screening. Genetics 143:973-982.

Gomez-Gomez, L., and Boller, T. 2000. FLS2: an LRR receptor-like kinase involved in the perception of the bacterial elicitor flagellin in Arabidopsis. Mol. Cell 5:1003-1012.

Hammerschmidt, R. 1999. Induced disease resistance: how do induced plants stop pathogens? Physiol. Mol. Plant Pathol. 55:77-84.

Hammerschmidt, R., and Kuć, J. 1982. Lignification as a mechanism for induced systemic resistance in cucumber. Physiol. Plant Pathol. 17:61-71.

Hammerschmidt, R., Métraux, J.-P., and Van Loon, L.C. 2001. Inducing resistance: a summary of papers presented at the First International Symposium on Induced Resistance to Plant Diseases, Corfu, May 2000. Eur. J. Plant Pathol. 107:1-6.

Hammond-Kosack, K.E., and Jones, J.D.G. 1996. Resistance gene-dependent plant defense responses. Plant Cell 8:1773-1791.

Heil, M., Hilper, A., Kaiser, W., and Linsenmair, K.E. 2000. Reduced growth and seed set following chemical induction of pathogen defence: does systemic acquired resistance (SAR) incur allocation costs? J. Ecol. 88:645-654.

Iavicoli, A., Boutet, E., Buchala, A., and Métraux, J.P. 2003. Induced systemic resistance in Arabidopsis thaliana in response to root inoculation with Pseudomonas fluorescens CHA0. Mol. Plant Microbe Interact. 16:851-858.

Kachroo, P., Yoshioka, K., Shah, J., Dooner, K.D., and Klessig, D.F. 2000. Resistance to turnip crinkle virus in Arabidopsis is regulated by two host genes and is salicylic 
acid dependent but NPR1, ethylene, and jasmonate independent. Plamt Cell 12:677690.

Katz, V.A., Thulke, O.U., and Conrath, U. 1998. A benzothiadiazole primes parsley cells for augmented elicitation of defense responses. Plant Physiol. 117:1333-1339.

Kauss, H., Franke, R., Krause, K., Conrath, U., Jeblick, W., Grimmig, B., and Matern, U. 1993. Conditioning of parsley (Petroselium crispum) suspension cells increases elicitorinduced incorporation of cell wall phenolics. Plant Physiol. 102:459-466.

Kauss, H., Jeblick, W., Ziegler, J., and Krabler, W. 1994. Pretreatment of parsley (Petroselinum crispum) L. suspension cultures with methyl jasmonate enhances elicitation of activated oxygen species. Plant Physiol. 105:89-104.

Kauss, H., Theisinger-Hinkel, E., Mindermann, R., and Conrath, U. 1992. Dichloroisonicotinic and salicylic acid, inducers of systemic acquired resistance, enhance fungal elicitor responses in parsley cells. Plant J. 2:655-660.

Kessmann, H., Staub, T., Ligon, J., Oostendorp, M., and Ryals, J. 1994. Activation of systemic acquired disease resistance in plants. Eur. J. Plant Pathol. 100:359-369.

Kloepper, J.W., Leong, J., Teintze, M., and Schroth, M.N. 1980. Enhanced plant growth by siderophores produced by plant growth-promoting rhizobacteria. Nature 286:885886.

Knoester, M., Linthorst, H.J.M., Bol, J.F., and Van Loon, L.C. 2001. Involvement of ethylene in lesion development and systemic acquired resistance in tobacco during the hypersensitive reaction to tobacco mosaic virus. Physiol. Mol. Plant Pathol. 59:45-57.

Knoester, M., Pieterse, C.M.J., Bol, J.F., and Van Loon. L.C. 1999. Systemic resistance in Arabidopsis induced by rhizobacteria requires ethylene-dependent signaling at the site of application. Mol. Plant Microbe Interact. 12:720-727.

Knoester, M., Van Loon, L.C., Van den Heuvel, J., Hennig, J., Bol, J.F., and Linthorst, H.J.M. 1998. Ethylene-insensitive tobacco lacks nonhost resistance against soil-borne fungi. Proc. Natl. Acad. Sci. USA 95:1933-1937.

Kovats, K., Binder, A., and Hohl, H.L. 1991. Cytology of induced systemic resistance of tomato to Colletotrichum lagenarium. Planta 183:484-490.

Kuć, J. 1982. Induced immunity to plant disease. Bioscience 32:854-860.

Lawton, K., Weymann, K., Friedrich, L., Vernooij, B., Uknes, S., and Ryals, J. 1995. Systemic acquired resistance in Arabidopsis requires salicylic acid but not ethylene. Mol. Plant Microbe Interact. 8:863-870.

Lawton, K.A., Friedrich, L., Hunt, M., Weymann, K., Delaney, T., Kessmann, H., Staub, T., and Ryals, J. 1996. Benzothiadiazole induces disease resistance in Arabidopsis by activation of the systemic acquired resistance signal transduction pathway. Plant J. 10:7182.

Lawton, K.A., Potter, S.L., Uknes, S., and Ryals, J. 1994. Acquired resistance signal transduction in Arabidopsis is ethylene independent. Plant Cell 6:581-588.

Leeman, M., Van Pelt, J.A., Den Ouden, F.M., Heinsbroek, M., Bakker, P.A.H.M., and Schippers, B. 1995a. Induction of systemic resistance against fusarium wilt of radish by lipopolysaccharides of Pseudomonas fluorescens. Phytopathology 85:1021-1027.

Leeman, M., Van Pelt, J.A., Den Ouden, F.M., Heinsbroek, M., Bakker, P.A.H.M., and Schippers, B. 1995b. Induction of systemic resistance by Pseudomonas fluorescens in radish cultivars differing in susceptibility to fusarium wilt, using a novel bioassay. Eur. J. Plant Pathol. 101:655-664.

Li, X., Zhang, Y., Clarke, J.D., Li, Y., and Dong, X. 1999. Identification and cloning of a negative regulator of systemic acquired resistance, SNI1, through a screen for suppressors of npr1-1. Cell 98:329-339. 
Liu, L., Kloepper, J.W., and Tuzun, S. 1995. Induction of systemic resistance in cucumber against angular leaf spot by plant growth-promoting rhizobacteria. Phytopathology 85:1064-1068.

Lund, S.T., Stall, R.E., and Klee, H.J. 1998. Ethylene regulates the susceptible response to pathogen infection in tomato. Plant Cell 10:371-382.

Lynch, J.M., and Whipps, J.M. 1991. Substrate flow in the rhizosphere. In The Rhizosphere and Plant Growth, eds. D.L. Keister, and P.B. Cregan, pp. 15-24. Dordrecht, The Netherlands: Kluwer.

Malamy, J., Carr, J.P., Klessig, D.F., and Raskin, I. 1990. Salicylic acid: a likely endogenous signal in the resistance response of tobacco to viral infection. Science 250:10021004.

Maleck, K., Levine, A., Eulgem, T., Morgan, A., Schmid, J., Lawton, K.A., Dangl, J.L., and Dietrich, R.A. 2000. The transcriptome of Arabidopsis thaliana during systemic acquired resistance. Nature Genet. 26:403-410.

Maurhofer, M., Hase, C., Meuwly, P., Métraux, J.P., and Défago, G. 1994. Induction of systemic resistance to tobacco necrosis virus by the root-colonizing Pseudomonas fluorescens strain CHA0: influence of the gacA gene and pyoverdine production. Phytopathology 84:139-146.

Maurhofer, M., Reimmann, C., Schmidli-Sacherer, P., Heeb, S.D., and Défago, G. 1998. Salicylic acid biosynthesis genes expressed in Pseudomonas fluorescens strain P3 improve the induction of systemic resistance in tobacco against tobacco necrosis virus. Phytopathology 88:678-684.

McConn, J., Creelman, R.A., Bell, E., Mullet, J.E., and Browse, J. 1997. Jasmonate is essential for insect defense in Arabidopsis. Proc. Natl. Acad. Sci. USA 94:5473-5477.

Métraux, J.P., Signer, H., Ryals, J., Ward, E., Wyss-Benz, M., Gaudin, J., Raschdorf, K., Schmid, E., Blum, W., and Inverardi, B. 1990. Increase in salicylic acid at the onset of systemic acquired resistance in cucumber. Science 250:1004-1006.

Meyer, J.-M., Azelvandre, P., and Georges, C. 1992. Iron metabolism in Pseudomonas: Salicylic acid, a siderophore of Pseudomonas fluorescens CHAO. Biofactors 4:23-27.

Mur, L.A.J., Naylor, G., Warner, S.A.J., Sugars, F.M., White, R.F., and Draper, J. 1996. salicylic acid potentiates defence gene expression in tissue exhibiting acquired resistance to pathogen attack. Plant J. 9:559-571.

Nawrath, C., and Métraux, J.P. 1999. Salicylic acid induction-deficient mutants of Arabidopsis express PR-2 and PR-5 and accumulate high levels of camalexin after pathogen inoculation. Plant Cell 11:1393-1404.

Norman-Setterblad, C., Vidal, S., and Palva, T.E. 2000. Interacting signal pathways control defense gene expression in Arabidopsis in response to cell wall-degrading enzymes from Erwinia carotovora. Mol. Plant Microbe Interact. 13:430-438.

Pallas, J.A., Paiva, N.L., Lamb, C., and Dixon, R.S. 1996. Tobacco plants epigenetically suppressed in phenylalanine ammonia-lyase expression do not develop systemic acquired resistance in response to infection by tobacco mosaic virus. Plant J. 10:281-293.

Pieterse, C.M.J., Van Pelt, J.A., Ton, J., Parchmann, S., Mueller, M.J., Buchala, A.J., Métraux, J.P., and Van Loon, L.C. 2000. Rhizobacteria-mediated induced systemic resistance (ISR) in Arabidopsis requires sensitivity to jasmonate and ethylene but is not accompanied by an increase in their production. Physiol. Mol. Plant Pathol. 57:123134.

Pieterse, C.M.J., Van Wees, S.C.M., Ton, J., Van Pelt, J.A., and Van Loon, L.C. 2002. Signalling in rhizobacteria-induced systemic resistance in Arabidopsis thaliana. Plant Biol. 4:535-544. 
Pieterse, C.M.J., Van Wees, S.C.M., Hoffland, E., Van Pelt, J.A., and Van Loon. L.C. 1996. Systemic resistance in Arabidopsis induced by biocontrol bacteria is independent of salicylic acid accumulation and pathogenesis-related gene expression. Plant Cell 8:1225 1237.

Pieterse, C.M.J., Van Wees, S.C.M., Van Pelt, J.A., Knoester, M., Laan, R., Gerrits, H., Weisbeek. P.J., and Van Loon. L.C. 1998. A novel signaling pathway controlling induced systemic resistance in Arabidopsis. Plant Cell 10:1571-1580.

Press, C.M., Wilson, M., Tuzun, S., and Kloepper, J.W. 1997. Salicylic acid produced by Serratiamarcescens 91-166 is not the primary determinant of induced systemic resistance in cucumber or tobacco. Mol. Plant Microbe Interact. 10:761-768.

Rogers, E.E., and Ausubel, F.M. 1997. Arabidopsis enhanced disease susceptibility mutants exhibit enhanced susceptibility to several bacterial pathogens and alterations in $P R-I$ gene expression. Plant Cell 9:305-316.

Ross, A.F. 1961. Systemic acquired resistance induced by localized virus infections in plants. Virology 14:340-358.

Ryals, J., Weymann, K., Lawton, K., Friedrich, L., Ellis, D., Steiner, H.Y., Johnson, J.. Delaney, T.P., Jesse, T., Vos, P., and Uknes, S. 1997. The Arabidopsis NIMl protein shows homology to the mammalian transcription factor inhibitor IkB. Plant Cell 9:425439

Ryals, J.A., Neuenschwander, U.H., Willits, M.G., Molina, A., Steiner, H.-Y., and Hunt, M.D. 1996. Systemic acquired resistance. Plant Cell 8:1808-1819.

Ryu, C.M., Hu, C.H., Reddy, M.S., and Kloepper, J.W. 2003. Different signaling pathways of induced resistance by rhizobacteria in Arabidopsis thaliana against two pathovars of Pseudomonas syringae. New Phytol. 160:413-420.

Schippers, B., Bakker, A.W., and Bakker, P.A.H.M. 1987. Interactions of deleterious and beneficial rhizosphere micoorganisms and the effect of cropping practices. Annu. Rev. Phytopathol. 115:339-358.

Shah, J., Tsui, F., and Klessig, D.F. 1997. Characterization of a salicylic acid-insensitive mutant (sail) of Arabidopsis thaliana, identified in a selective screen utilizing the SA-inducible expression of the tms2 gene. Mol. Plant Microbe Interact. 10:6978.

Shulaev, V., Leon, J., and Raskin, I. 1995. Is salicylic acid a translocated signal of systemic acquired resistance in tobacco? Plant Cell 7:1691-1701.

Smith-Becker, J., Marois, E., Huguet, E.J., Midland, S.L., Sims, J., and Keen, N.T. 1998. Accumulation of salicylic acid and 4-hydroxybenzoic acid in phloem fluids of cucumber during systemic acquired resistance is preceded by a transient increase in phenylalanine ammonia-lyase activity in petioles and stems. Plant Physiol. 116:231238.

Staswick, P.E., Yuen, G.Y., and Lehman, C.C. 1998. Jasmonate signaling mutants of Arabidopsis are susceptible to the soil fungus Pythium irregulare. Plant J. 15:747-754.

Sticher, L., Mauch-Mani, B., and Métraux, J.-P. 1997. Systemic acquired resistance. Annu. Rev. Phytopathol. 35:235-270.

Stout, M.J., Fidantsef, A.L., Duffey, S.S., and Bostock, R.M. 1999. Signal interactions in pathogen and insect attack: systemic plant-mediated interactions between pathogens and herbivores of the tomato, Lycopersicon esculentum. Physiol. Mol. Plant Pathol. 54:115130 .

Thomma, B.P.H.J., Eggermont, K., Broekaert, W.F., and Cammue, B.P.A. 2000. Disease development of several fungi on Arabidopsis can be reduced by treatment with methyl jasmonate. Plant Physiol. Biochem. 38:421-427. 
Thomma, B.P.H.J., Eggermont, K., Penninckx, I.A.M.A., Mauch-Mani, B., Vogelsang, R., Cammue, B.P.A., and Broekaert, W.F. 1998. Separate jasmonate-dependent and salicylate-dependent defense-response pathways in Arabidopsis are essential for resistance to distinct microbial pathogens. Proc. Natl. Acad. Sci. USA 95:1510715111.

Thomma, B.P.H.J., Eggermont, K., Tierens, K.F.M., and Broekaert, W.F. 1999. Requirement of functional ethylene-insensitive 2 gene for efficient resistance of Arabidopsis to infection by Botrytis cinerea. Plant Physiol. 121:1093-1102.

Thulke, O.U., and Conrath, U. 1998. Salicylic acid has a dual role in the activation of defense-related genes in parsley. Plant J. 14:35-42.

Ton, J., Davison, S., Van Wees, S.C.M., Van Loon, L.C., and Pieterse, C.M.J. 2001. The Arabidopsis ISR I locus controlling rhizobacteria-mediated induced systemic resistance is involved in ethylene signaling. Plant Physiol. 125:652-661.

Ton, J., De Vos, M., Robben, C., Buchala, A.J., Métraux, J.P., Van Loon, L.C., and Pieterse, C.M.J. 2002a. Characterisation of Arabidopsis enhanced disease susceptibility mutants that are affected in systemically induced resistance. Plant J. 29:1121.

Ton, J., Pieterse, C.M.J., and Van Loon, L.C. 1999. Identification of a locus in Arabidopsis controlling both the expression of rhizobacteria-mediated induced systemic resistance (ISR) and basal resistance against Pseudomonas syringae pv. tomato. Mol. Plant Microbe Interact. 12:911-918.

Ton, J., Van Pelt, J.A., Van Loon, L.C., and Pieterse, C.M.J. 2002b. The Arabidopsis ISRI locus is required for rhizobacteria-mediated induced systemic resistance against different pathogens. Plant Biol. 4:224-227.

Ton, J., Van Pelt, J.A., Van Loon, L.C., and Pieterse, C.M.J. 2002c. Differential effectiveness of salicylate-dependent and jasmonate/ethylene-dependent induced resistance in Arabidopsis. Mol. Plant Microbe Interact. 15:27-34.

Uknes, S., Mauch-Mani, B., Moyer, M., Potter, S., Williams, S., Dincher, S., Chandler, D., Slusarenko, A., Ward, E., and Ryals, J. 1992. Acquired resistance in Arabidopsis. Plant Cell 4:645-656.

Van Loon, L.C. 1997. Induced resistance and the role of pathogenesis-related proteins. Eur. J. Plant Pathol. 103:753-765.

Van Loon, L.C., and Antoniw, J.F. 1982. Comparison of the effects of salicylic acid and ethephon with virus-induced hypersensitivity and acquired resistance in tobacco. Neth. J. Plant Pathol. 88:237-256.

Van Loon, L.C., Bakker, P.A.H.M., and Pieterse, C.M.J. 1998. Systemic resistance induced by rhizosphere bacteria. Annu. Rev. Phytopathol. 36:453-483.

Van Peer, R. 1990. Microbial interactions and plant responses in soilless cultures-root colonization by pseudomonads: mechanisms, plant responses and effects on fusarium wilt. Ph. D. thesis, Utrecht University, The Netherlands.

Van Peer, R., Niemann, G.J., and Schippers, B. 1991. Induced resistance and phytoalexin accumulation in biological control of fusarium wilt of carnation by Pseudomonas sp. strain WCS417r. Phytopathology 91:728-734.

Van Peer, R., and Schippers, B. 1992. Lipopolysaccharides of plant growth-promoting Pseudomonas sp. strain WCS417r induce resistance in carnation to fusarium wilt. Neth. J. Plant Pathol. 98:129-139.

Van Wees, S.C.M. 1999. Rhizobacteria-mediated induced systemic resistance in Arabidopsis: signal transduction and expression. Ph. D. thesis, Utrecht University, The Netherlands. 
Van Wees, S.C.M., De Swart. E.A.M., Van Pelt. J.A., Van Loon. L.C., and Pieterse, C.M.J. 2000. Enhancement of induced disease resistance by simultaneous activation of salicylate- and jasmonate-dependent defense pathways in Arabidopsis thaliana. Proc. Natl. Acad. Sci. USA 97:8711-8716.

Van Wees, S.C.M., Luijendijk, M., Smoorenburg, I., Van Loon, L.C., and Pieterse, C.M.J. 1999. Rhizobacteria-mediated induced systemic resistance (ISR) in Arabidopsis is not associated with a direct effect on expression of known defense-related genes but stimulates the expression of the jasmonate-inducible gene Atvsp upon challenge. Plant Mol. Biol. 41:537-549.

Van Wees, S.C.M., Pieterse, C.M.J., Trijssenaar, A., Van 't Westende, Y.A.M., Hartog, F., and Van Loon, L.C. 1997. Differential induction of systemic resistance in Arabidopsis by biocontrol bacteria. Mol. Plant Microbe Interact. 10:716-724.

Verberne, M.C., Hoekstra, J., Bol, J.F., and Linthorst, H.J.M. 2003. Signaling of systemic acquired resistance in tobacco depends on ethylene perception. Plant J. 35:2732.

Vernooij, B., Friedrich, L., Morse, A., Reist, R., Kolditz-Jawhar, R., Ward, E.. Uknes, S., Kessmann, H., and Ryals, J. 1994. Salicylic acid is not the translocated signal responsible for inducing systemic acquired resistance but is required in signal transduction. Plant Cell 6:959-965.

Vijayan, P., Shockey, J., Levesque, C.A., Cook, R.J., and Browse, J. 1998. A role for jasmonate in pathogen defense of Arabidopsis. Proc. Natl. Acad. Sci. USA 95:72097214.

Visca, P., Ciervo, A., Sanfilippo, V., and Orsi, N. 1993. Iron-regulated salicylate synthesis by Pseudomonas spp. J. Gen. Microbiol. 139:1995-2001.

Volko, S.M., Boller, T., and Ausubel, F.M. 1998. Isolation of new Arabidopsis mutants with enhanced disease susceptibility to Pseudomonas syringae by direct screening. Genetics 149:537-548.

Ward, E.R., Uknes, S.J., Williams, S.C., Dincher, S.S., Wiederhold, D.L., Alexander, D.C., Ahl-Goy, P., Métraux, J.P., and Ryals, J.A. 1991. Coordinate gene activity in response to agents that induce systemic acquired resistance. Plant Cell 3:1085-1094.

Wei, G., Kloepper, J.W., and Tuzun, S. 1991. Induction of systemic resistance of cucumber to Colletotichum orbiculare by select strains of plant-growth promoting rhizobacteria. Phytopathology 81:1508-1512.

Wei, G., Kloepper, J.W., and Tuzun, S. 1996. Induced systemic resistance to cucumber diseases and increased plant growth by plant growth-promoting rhizobacteria under field conditions. Phytopathology 86:221-224.

Whalen, M.C., Innes, R.W., Bent, A.F., and Staskawicz, B.J. 1991. Identification of Pseudomonas syringae pathogens of Arabidopsis and a bacterial locus determining avirulence on both Arabidopsis and soybean. Plant Cell 3:49-59.

White, R.F. 1979. Acetylsalicylic acid (aspirin) induces resistance to tobacco mosaic virus in tobacco. Virology 99:410-412.

Wildermuth, M.C., Dewdney, J., Wu, G., and Ausubel, F.M. 2001. Isochorismate synthase is required to synthesize salicylic acid for plant defence. Nature 414:562-565.

Yan, Z., Reddy, M.S., Ryu, C.M., McInroy, J.A., Wilson, M., and Kloepper, J.W. 2002. Induced systemic protection against tomato late blight elicited by plant growth-promoting rhizobacteria. Phytopathology 92:1329-1333.

Zhang, Y., Fan, W., Kinkema, M., Li, X., and Dong, X. 1999. Interaction of NPR 1 with basic leucine zipper protein transcription factors that bind sequences required for salicylic acid induction of the PR-I gene. Proc. Natl. Acad. Sci. USA 96:6523-6528. 
Zhou, J.M., Trifa, Y., Silva, H., Pontier, D., Lam, E., Shah, J., and Klessig, D.F. 2000. NPR1 differentially interacts with members of the TGA/OBF family of transcription factors that bind an element of the $P R-1$ gene required for induction by salicylic acid. Mol. Plant-Microbe Interact. 13:191-202.

Zimmerli, L., Jakab, G., Métraux, J.-P., and Mauch-Mani, B. 2000. Potentiation of pathogenspecific defense mechanisms in Arabidopsis by $\beta$-aminobutyric acid. Proc. Natl. Acad. Sci. USA 97:12920-12925. 